\title{
The Effect of Torrefaction on Syngas Quality Metrics from Fluidized Bed Gasification of SRC Willow
}

\author{
K. Woytiuk, W. Campbell, R.Gerspacher, R.W. Evitts, A. Phoenix \\ Department of Chemical and Biological Engineering University of Saskatchewan, 57 Campus
}

Drive, Saskatoon SK Canada, S7N 5A9,e-mail:kurt.woytiuk@usask.ca,ph: 306-966-6494

\begin{abstract}
Short rotation coppice willow is proposed as a dedicated energy crop in the Canadian prairie region. A coppice willow hybrid known as SV1 (Salix Dasyclados) grown at the University of Saskatchewan was torrefied in a continuous torrefaction reactor at four temperatures $(240,260$, 270 and $280^{\circ} \mathrm{C}$ ). The torrefied and control samples were then ground and gasified in a fluidized bed reactor at $900{ }^{\circ} \mathrm{C}$ with air and steam. The samples were characterized for ultimate composition and lignocelluloses. A unique HR-TGA method was used to determine the fraction of hemicelluloses, cellulose, lignin and ash in the torrefied and control samples. Syngas quality was evaluated based on gas yield and tar concentration. Tars were measured using a flame ionization detector and gas chromatograph. The syngas yield was found to increase from 2.02 to $2.47 \mathrm{~m}^{3} / \mathrm{kg}_{\mathrm{SV} 1}$ between the non-torrefied and heavily torrefied samples. Tar yield was observed to decrease from $17.26 \mathrm{~g} / \mathrm{m}^{3}$ (mean for the control and the $240{ }^{\circ} \mathrm{C}$ conditions) to $9.21 \mathrm{~g} / \mathrm{m}^{3}$ (mean for the 260,270 and $280{ }^{\circ} \mathrm{C}$ conditions) a reduction of $47 \%$. The change in syngas quality coincides with the degradation of hemicelluloses below approximately $12 \%$ dry weight. More severe torrefaction had no additional effect on the syngas quality metrics.
\end{abstract}

\section{Key Words}

Torrefaction, fluidized bed gasification, SRC willow, tar yield 


\section{Introduction}

Torrefaction is a promising pretreatment for underutilized biomass resources in North America. A mild form of pyrolysis, torrefaction involves heating biomass in the absence of oxygen to between 230 and $300{ }^{\circ} \mathrm{C}$ [1]. The structure of the biomass changes as oxygenated compounds are volatilized. The main effect of interest is the reduction in the polymer hemicellulose from the biomass structure. Hemicelluloses begin to volatilize at approximately $250{ }^{\circ} \mathrm{C}$ [2]. Hydrolysis first causes hemicelluloses to depolymerize, followed by a series of acid and radical reactions which release acids and water [3]. The water and acids formed by these reactions are then available to also depolymerize cellulose and lignin, but to a much lesser extent. Overall, the result is a lower $\mathrm{O} / \mathrm{C}$ and $\mathrm{H} / \mathrm{C}$ ratio in the solid product that in turn, increases the energy density and reduces the required comminution energy. Three recent reviews summarize the state-of-theart of torrefaction and the benefits to biomass processes [4-6]. In short, torrefied biomass can be conveyed, stored and pulverized in a similar manner to coal, a common fuel for electricity generation.

Independent of torrefaction, researchers have shown short-rotation coppice willow (SRCW) to yield significantly more energy and output significantly less GHG emissions [7]. Djomo et al. reviewed 26 studies and found, on average, SRCW to yield 36 times more energy per unit of fossil fuel energy input and 24 times lower GHG emissions compared to coal. Co-firing ratios in existing coal-fired power infrastructure are limited to approximately $10 \%$ due to the behavior of biomass in suspension burning systems [8]. Recently, a 100\% substitution of coal with torrefied biomass in a pulverized coal-fired boiler was suggested with no loss of boiler efficiency or fluctuation in load [9]. With consideration of the associated operational problems (slagging, fouling and corrosion), the modeled reduction in $\mathrm{CO}_{2}$ and $\mathrm{NO}_{\mathrm{x}}$ emissions presented by Li et al. [9] is promising.

Beyond co-firing, torrefied biomass has been proven to be a valuable feedstock for gasification leading to a wider range of energy applications. Replacement of fossil derived transportation fuels with synthetic fuels from biomass-to-liquids processes is of particular interest owing to the lack of viable alternatives [10]. Early investigation into the area of gasification of torrefied biomass considered the benefits of handling and fluidization as a result of the characteristics of torrefied biomass. The reduction of net hemicelluloses through torrefaction was reported to result in ground biomass particles with a lower length-to-diameter ratio capable of smooth fluidization required for entrained flow (EF) gasification [11]. More specifically, particles could be pulverized to behave like Geldart type A powders as required for fast fluidization [12]. By studying torrefied wood gasified in a circulating fluidized bed (CFB), an EF reactor and an oxygen-blown EF reactor, Prins et al. [12] were able to conclude that, in addition to the improved fluidization characteristics, decoupling torrefaction reactions from the gasifier increases the efficiency of high temperature gasification. The increase in available energy is, however, dependent on the use of both the char and volatile gases from torrefaction in the gasification process. More recent studies have expanded the understanding. In a steam injected 
EF gasifier at $1400{ }^{\circ} \mathrm{C}$, Couhert et al. [13] were able to produce $7 \% \mathrm{~g} / \mathrm{g}_{\text {dry wood }}$ more $\mathrm{H}_{2}$ and 20 $\% \mathrm{~g} / \mathrm{g}_{\text {dry wood }}$ more $\mathrm{CO}$ from torrefied versus non-torrefied beechwood, consistent with the increase in carbon and hydrogen fraction in the feedstock. In a similar study, Chen et al. [14] gasified sawdust without the application of steam. The study showed improvements in the syngas quality, but a reduction in the gasification efficiency unless the torrefaction gases were consumed in the gasifier.

Few studies relating to the gasification of torrefied biomass consider the 'cleanliness' of the product or syngas. Production of clean syngas accounts for the majority of capital expenses in modern biomass-to-liquids processes, as high as $70 \%$ [15]. The main impurities in syngas are tars, particulates, nitrogen and sulphur. Tar in particular is both costly to remove from the gas stream and damaging to downstream equipment surfaces that are below the dewpoint temperature of the vapour mixture. The dewpoint temperature can be as high as $450{ }^{\circ} \mathrm{C}$ [16].Tar formation has been linked to biomass composition by multiple studies. Milne et al. [17] defined primary tars as those derived from macromolecules cellulose, hemicellulose and lignin. Others have gasified individual components to connect tar yield and tar species to carbohydrates and lignin $[18 ; 19]$. Finally, researchers have shown a decrease in tar yield by comparing syngas from a torrefied and non-torrefied feedstock [20-22]. Dudyński et al. reported a reduction of tar mass from $0.0210 \mathrm{~kg} / \mathrm{kg}_{\text {fuel }}$ to $0.0138 \mathrm{~kg} / \mathrm{kg}_{\text {fuel }}$ in an industrial fixed-bed gasifier between untreated sawdust and torrefied pellets [22]. However, the gasification temperatures were inconsistent between tests and definitive conclusions relating tar concentration to torrefaction were not possible.

In this work, a continuous torrefaction reactor was used to torrefy short-rotation coppice willow samples at four temperatures. The resulting biomass was analyzed and gasified in a bubbling fluidized bed gasifier with steam and air under fixed and steady-state conditions. The scope presupposes a techno-economic benefit to producing torrefied SRC willow for co-firing with coal and includes value-added processing via gasification. The objective is to correlate lignocellulose composition with syngas quality using rapid analysis techniques. The resulting syngas analysis provides insight into syngas quality and tar yield based on biomass composition prior to gasification.

The novelty in this work is in application of rapid analysis techniques for process development. Analysis of syngas from fluidized bed gasification is used as feedback to determine the conditions in an upstream torrefaction process. The data and methods presented here can be used to change the willow composition during the torrefaction process in order to produce low-tar syngas from fluidized bed gasification. By changing the feedback information from tar yield and $\mathrm{H}_{2} / \mathrm{CO}$ ratio to, for example, heating value of syngas or hydrophobicity of the willow, torrefaction parameters for other applications could be established. 


\section{Materials and Methods}

Lignocelluloses are controlled using a continuous torrefaction system and measured using a high-resolution thermogravimetric method developed by the State University of New York College of Environmental Science and Forestry (SUNY-ESF). The torrefied and non-torrefied willow is gasified in a $75 \mathrm{~mm}$ diameter bubbling fluidized bed with steam and air. Tar yield is quantified by comparing a gas-chromatogram to a total hydrocarbon concentration from a flame ionization detector similar to the method of Moersch et al. [23].

\subsection{Biomass}

Coppice willow is a promising feedstock for bioenergy applications in Northern regions. A plantation of 28 varieties of hybrid willow was established in 2007 on the University of Saskatchewan campus (Saskatoon, Canada). For this work, the shrub willow hybrid named 'SV1' (Salix Dasyclados) was selected. It is a well-known hybrid with disease and pest resistance and has produced high yields in a variety of soil conditions [24]. In the $2^{\text {nd }}$, three-year cycle, after 1 year of growth, the willows were harvested by hand. The stems were collected and sorted. Stems approximately $1.25 \mathrm{~cm}$ in diameter or less were cut to $2.5 \mathrm{~cm}$ lengths using a rotary cutting machine [25]. The equipment produces approximately pellet sized segments of willow that flow easily through a screw auger system. The cut biomass was then stored at $4{ }^{\circ} \mathrm{C}$ to prevent significant degradation. In storage the stems dried to approximately $10 \%$ moisture content. Cut pieces were then further dried at $150{ }^{\circ} \mathrm{C}$ in a continuous, moving bed torrefaction unit (CTU) operating as an air-dryer. Dried willow pieces retained a moisture content of approximately $5 \%$. Moisture content between 3 and $20 \%$ was necessary to prevent adverse effects of reduced mass and energy yield and reduced energy density as a result of accelerated polymer decomposition reactions [2]. All moisture content is reported on a wet basis.

SV1 willow pieces were torrefied at four temperatures $\left(240,260,270\right.$ and $\left.280{ }^{\circ} \mathrm{C}\right)$ in the $\mathrm{CTU}$ using nitrogen gas as the heating medium rather than air. Development of the reactor is the topic of a parallel project and details will be published elsewhere. The direct heating method and moving bed allows for lower residence time relative to other torrefaction processes. Typically, torrefaction times range from 10 to 60 minutes whereas in this work, samples were processed for 10 minutes including drying, intermediate heating, heating and torrefaction as described by Bergman and Kiel [11]. Earlier work showed the effects of residence time within the range of interest (10-30 minutes) did not have an appreciable impact on biomass characteristics and the residence time was fixed at 10 minutes for these experiments [26]. The particles reached peak temperature in the last third of the reactor length. Peak particle temperature has a pronounced effect on biomass compared to the effect of residence time [2]. Torrefied and control (untreated) samples were then ground using a \#1 Wiley mill operated by a $1 \mathrm{HP}$ variable speed drive at 878 rpm with a $1.88 \mathrm{~mm}$ mesh screen. 


\subsection{Characterization}

The relative lignocellulose composition was determined using high-resolution thermogravimetric analysis (HR-TGA). The analysis method was developed by SUNY-ESF for the purposes of breeding shrub willow (Salix spp.) for biomass and environmental applications [27; 28]. In the early method development, Serapiglia et al.compared macro-molecular composition using well established wet chemical methods (TAPPI standard T $204 \mathrm{om}-88$ and T $222 \mathrm{om}-88$ ) to the highresolution TGA method [27]. The resulting linear regressions ( $\mathrm{p}$-value<0.0001) had r-squared values greater than 0.7 . The HR-TGA method reduces laboratory time, requires lower sample mass and eliminates sources of error relative to the wet chemical methods. The method is limited to shrub willow biomass and does not provide individual carbohydrate content. Rapid analysis is excellent for process control and verification of biomass quality prior to downstream processes such as gasification. The thermograms in this work were collected using a TGA/DSC (Q600, TA Instruments, US). Analysis was done in collaboration with Serapiglia et al. to determine the relative lignocellulose composition of the feedstocks [27; 28]. The instrument is set to "highresolution dynamic" mode and the method involves a heating rate of $20^{\circ} \mathrm{C} / \mathrm{min}$, a peak temperature of $600{ }^{\circ} \mathrm{C}$, resolution of 4.0 and sensitivity setting of 1.0.

Ultimate composition of the treated and untreated willow was determined using a CHNS analyzer (VarioEL III, Elementar, DE) and a microbalance (XP6,Mettler Toledo, US) with a range of up to $5.1 \mathrm{~g}$ with a $1 \mu \mathrm{g}$ precision. Once the CHNS composition was determined, oxygen content was calculated by difference. The ultimate composition was used to calculate the lower heating value of the biomass using an established empirical correlation shown as Eq. 1 [29].

$L H V=(349.1 C+1178.3 H+100.5 S-103.4 O-15.1 N-21.1 A S H)-2260\left(\frac{9 H}{100}-\frac{M}{100}\right)$

Where $\mathrm{C}, \mathrm{H}, \mathrm{S}, \mathrm{O}$ and $\mathrm{N}$ are the constituent elements of the feedstock on a percent dry weight basis. Ash and $\mathrm{M}$ are the mineral content and moisture content on a dry weight basis. Eq. 1 represents the lower heating value in $\mathrm{kJ} / \mathrm{kg}$.

Ash content of each sample is determined to be the stable mass remaining following thermogravimetric analysis and moisture $(\mathrm{M})$ is measured using a halogen moisture analyzer (HB43 Metler Toledo, CH).

\subsection{Apparatus}

A $75 \mathrm{~mm}$ diameter tubular thermal reactor was used for gasification of the willow. Figure 1 shows the main components of the reactor. The windbox and steam generator are heated using external heating tapes set at $200{ }^{\circ} \mathrm{C}$. The feeding tube is located between T101 and T103 directly above the distributor plate. The distributor consists of a punched plate with a wire mesh above to hold fine particles within the reactor section. The auger extends into the silica bed and is purged using nitrogen to prevent backflow of silica sand into the feed hopper. The pressure sensor P02 shown in Figure 1 is purged with helium to prevent the flow of sand from the bed. Heat is added to the silica bed through a $3000 \mathrm{~W}$ ATS electric clamshell furnace. The freeboard is 
approximately $1 \mathrm{~m}$ in height and an expansion in the freeboard diameter reduces entrainment of particulates into the gas cleaning section. Above the freeboard, a swirling water-cooled condenser and cyclone are used to cool the gas and condense organics prior to gas evacuation.

Fig.1 Fluidized bed gasifier piping and instrumentation diagram

Data acquisition is performed using two Omega 8-channel data loggers measuring temperatures and pressures throughout the bed as well as the output from the total hydrocarbon analyzer. Temperature and pressure measurement ports are shown in Figure 1. Pressure sensors are located in the freeboard, the fluidized bed and the directly below the bed.

Untreated and torrefied samples were gasified in the fluidized bed reactor. The samples were exposed to a bubbling bed of silica sand heated to $900{ }^{\circ} \mathrm{C}$. The silica bed is $11 \mathrm{~cm}$ deep with a Sauter mean diameter of $250 \mu \mathrm{m}$ and particle density of $2600 \mathrm{~kg} / \mathrm{m}^{3}$. Steam was used to promote the production of hydrogen in the reforming reaction. $0.1 \mathrm{~g} / \mathrm{s}$ on a dry basis of each feedstock was fed to the reactor via the auger feed system. The system was calibrated prior to each run and verified post run by measuring the weight of the hopper. Air and Nitrogen were used to maintain fluidization with a low equivalence ratio (ER) of approximately 0.09. The steam and air flowrates were adjusted for each experiment based on the moisture and characteristics of the feedstock. Table 1 shows the design and actual experimental conditions.

Table 1:

Design and actual gasification conditions of four torrefied willow samples and the control sample. Design conditions are based on biomass characterization data with actualconditions (in brackets) determined following each experiment.

\begin{tabular}{|c|c|c|c|c|c|}
\hline Parameter & Untreated & @ $240^{\circ} \mathrm{C}$ & $@ 260^{\circ} \mathrm{C}$ & $@ 270^{\circ} \mathrm{C}$ & @ $280^{\circ} \mathrm{C}$ \\
\hline Feedrate $(\mathrm{g} / \mathrm{s})$ & $0.100(\boldsymbol{0 . 1 0 1})$ & $0.100(0.103)$ & $0.100(0.100)$ & $0.100(\boldsymbol{0 . 1 0 0})$ & $0.100(0.101)$ \\
\hline Steam (g/s) & $0.061(0.057)$ & $0.062(\mathbf{0 . 0 6 1})$ & $0.063(\mathbf{0 . 0 6 3 )}$ & $0.066(0.059)$ & $0.065(\mathbf{0 . 0 6 3 )}$ \\
\hline Fluidization Air $(\mathrm{g} / \mathrm{s})$ & $0.071(\boldsymbol{0 . 0 6 2})$ & $0.072(\boldsymbol{0 . 0 7 1})$ & $0.074(0.072)$ & $0.077(\boldsymbol{0 . 0 6 9})$ & $0.076(\mathbf{0 . 0 7 3})$ \\
\hline Fuel-bound Oxygen $(\mathrm{g} / \mathrm{s})$ & $(0.042)$ & $(0.042)$ & $(0.040)$ & $(0.038)$ & $(0.038)$ \\
\hline Nitrogen* $(\mathrm{g} / \mathrm{s})$ & $(0.080)$ & $(0.082)$ & $(0.084)$ & $(0.080)$ & $(0.085)$ \\
\hline Equivalence Ratio & $0.085(\mathbf{0 . 0 7 3})$ & $0.085(\mathbf{0 . 0 8 2})$ & $0.085(0.084)$ & $0.085(\boldsymbol{0 . 0 7 6})$ & $0.085(0.081)$ \\
\hline
\end{tabular}

*the sum of compressed gas $(0.027 \mathrm{~g} / \mathrm{s})$ and atmospheric nitrogen

\section{$2.4 \quad$ Analysis}

Quantification of tar yield is carried out by comparing a 'clean' gas stream free of particulate and cooled to ambient temperatures to a 'dirty', hot gas stream (having passed through a particulate filter). Samples are taken $50 \mathrm{~cm}$ above the fluidized bed using a KNF diaphragm vacuum pump. The flow is split into two streams and the clean gas is analyzed for gaseous hydrocarbons and inert gases in a gas chromatograph (4900 micro-GC, Agilent, US). The unfiltered, 'dirty' gas is maintained at $200{ }^{\circ} \mathrm{C}$ using heating tape and passed through a 7 micron particulate filter before entering an online flame ionization detector that outputs the methane equivalent total hydrocarbons (3000HM Signal Instrument Company, US).The device has a range of up to $10 \%$ methane equivalent hydrocarbons with accuracy of $\pm 1 \%$ or $\pm 0.2 \mathrm{ppm}$. Flame ionization detection 
has been used previously to quantify the fraction of tar in syngas [23]. However, in this work, the 'cleaned' gas sample is analyzed in a GC/FID as opposed to using the same FID analyzer for both samples. The calculation of tar yield is shown in section 3 .

The 'clean' sample is passed through a filter/condenser train consisting of two spin-on oil filter cartridges in an ice bath and a 7 micron inline filter. The cleaned gas is passed through a loop to the micro-GC and analyzed every 2.5 minutes.

The GC output is compared to the FID output on a 10 second frequency. The samples are taken from the same point in the reactor, however, owing to the differences in distance and volume between the two systems, the exact time of measurement is unknown. To account for the variation, the FID output is averaged across the preceding 2.5 minute period and compared to the sum of the hydrocarbons from the GC measurement. Each experiment lasted 70 minutes allowing 30 minutes to reach steady state and 40 minutes for data collection and producing fifteen data points. The control sample (untreated SV1) was gasified in three independent runs and torrefied samples were gasified in two runs.

The primary source of error in determination of tar yield using flame ionization detection is the flow rates of the carrier gas, hydrogen, and air [30]. Notable instances of reduced flow-rates occur due to temperature changes in pressure-controlled systems. Barwick reported that changes of $+/-1 \mathrm{ml} / \mathrm{min}$ resulted in a change in detector sensitivity anywhere from $1 \%$ to $5 \%$. She also stated that increased flow-rates of carrier gas result in greater noise in the measurement. In the current gasification experiments, temperatures were stabilized during the ramping period prior to data collection. Bed temperatures were controlled to approximately $+/-0.9{ }^{\circ} \mathrm{C}$ during data collection.

During the experiments, fly ash in the FID sampling system proved to be a major concern. The 7 micron filter upstream of the FID was changed out for each experiment and an $\mathrm{N}_{2}$ purge system was used to maintain a consistent flow-rate to the FID. Any system incorporating FID analysis of syngas should employ in-situ fly ash removal prior to sampling.

\section{Theory / Calculation}

Tars as defined in this work, represent all condensable organics in the syngas as measured using the method described in section 2 with a molecular weight greater than Propane. Differentiation between primary, secondary or tertiary tars has not been made.

Concentration of tar is determined using relative response factors for methane equivalent total hydrocarbons. The GC output was calibrated to include $\mathrm{H}_{2}, \mathrm{CO}, \mathrm{CO}_{2}, \mathrm{CH}_{4}, \mathrm{C}_{2} \mathrm{H}_{4}, \mathrm{C}_{2} \mathrm{H}_{6}, \mathrm{C}_{3} \mathrm{H}_{8}$ / $\mathrm{C}_{3} \mathrm{H}_{6}, \mathrm{C}_{2} \mathrm{H}_{2}, \mathrm{O}_{2}, \mathrm{~N}_{2}$ and $\mathrm{He}$. Propane and Propylene co-elute producing a single combined fraction. The relative sensitivity and response factors for each hydrocarbon in this output are included in Table 2. The tar yield is calculated as is shown in Eq.2.

$$
\text { Tar }=\text { THC }_{C_{4} H_{4 q}}-\sum_{i}[H C]_{i} \times R R_{i}
$$


Where THC is the output from the total hydrocarbon analyzer, $[\mathrm{HC}]_{\mathrm{i}}$ is volume percent of each hydrocarbon output by the GC-FID and $\mathrm{RR}_{\mathrm{i}}$ is the relative response factor for each hydrocarbon. The relative response factors for are calculated according to Eq. 3.

Relative Response Factor ${ }_{C_{x} H_{y}}=\left[\frac{\text { Rel Sensitivity } C_{X^{\prime} H_{y}} \times M W_{C_{x} H_{y}}}{\text { Rel Sensitivty }{ }_{C_{4}} \times M W_{C_{4}}}\right]$

Table2

Relative sensitivity data and calculated relative responsefactors

\begin{tabular}{lcc} 
& Relative Sensitivity & Relative Response Factor \\
\hline Methane & 0.97 & 1 \\
Ethane & 0.97 & 1.87 \\
Ethylene & 1.02 & 1.84 \\
Propane & 0.98 & 2.78 \\
Propylene & 0.93 & 2.52 \\
Acetylene & 1.07 & 1.79 \\
\hline
\end{tabular}

All gas volumes reported in this work are at normal temperature and pressure $(101.3 \mathrm{kPa}$ and 20 $\left.{ }^{\circ} \mathrm{C}\right)$. Reported error reflects the random uncertainty for a population of independent experimental measurements at a $95 \%$ confidence level. The mass of samples reported are on a dry, ash-free (daf) basis unless otherwise stated.

Fig.2 Mass and energy yield of SRC willow torrefied at four temperatures

\section{Results and Discussion}

Mass loss and energy yield provide a measure of the effectiveness of the torrefaction system. Mass loss is the ratio of final mass to starting mass and energy yield is defined by Eq. 4 .

$E_{y i e l d}=\left[\frac{\text { Final Mass } \times L H V_{\text {sample }}}{\text { Starting Mass } \times L H V_{\text {control }}}\right]$

The increase in calorific value is balanced against the loss of volatile mass from the treated energy feedstock. Figure 2 shows the energy yield which decreases from $94 \%$ to $88 \%$ across the temperature range.

The relative proportions of cellulose, hemicellulose and lignin are shown in Table 3. Others have reported lignin fractions between 21 and $22 \%$ for SV1 after 3 years of growth [31]. The lignin fraction of willow harvested after 1 year of growth is expected to be high and this appears to be the case. Lignin-rich woody biomass has been shown to have greater calorific value compared to biomass with higher carbohydrate composition [32]. Analysis of the torrefied willow samples shows a positive correlation between lignin and heating value. The increase in lignin of $7.1 \%$ dry weight (dw) across the samples corresponds to an increase in heating value of $1.7 \mathrm{MJ} / \mathrm{kg}$ (Pearson's coefficient of 0.980). The uniform degradation of hemicelluloses across the experimental torrefaction temperature range, in conjunction with the mass and energy yield, is demonstrative of the degree of torrefaction possible from the CTU. 
Table 3

Lignocellulose composition of torrefied and non-torrefied SV1 willowdetermined by HR-TGA [27] (\% dry weight)

\begin{tabular}{|c|c|c|c|c|c|c|c|c|}
\hline & \multicolumn{2}{|c|}{ Cellulose } & \multicolumn{2}{|c|}{ Hemicellulose } & \multicolumn{2}{|c|}{ Lignin } & \multicolumn{2}{|c|}{ Ash } \\
\hline Untreated & 43.2 & $+/-2.1$ & 18.5 & $+/-0.2$ & 26.8 & $+/-0.9$ & 1.9 & $+/-1.3$ \\
\hline @ $240{ }^{\circ} \mathrm{C}$ & 44.9 & $+/-3.5$ & 15.5 & $+/-0.1$ & 28.5 & $+/-3.8$ & 2.3 & $+/-<0.1$ \\
\hline (a) $260{ }^{\circ} \mathrm{C}$ & 48.2 & $+/-1.1$ & 10.9 & $+/-1.3$ & 29.4 & $+/-0.6$ & 2.4 & $+/-0.3$ \\
\hline (a) $270{ }^{\circ} \mathrm{C}$ & 49.0 & $+/-1.8$ & 5.7 & $+/-0.8$ & 32.2 & $+/-0.8$ & 2.6 & $+/-0.3$ \\
\hline @ $280{ }^{\circ} \mathrm{C}$ & 49.7 & $+/-0.1$ & 3.4 & $+/-0.4$ & 33.9 & $+/-1.5$ & 2.4 & $+/-0.7$ \\
\hline
\end{tabular}

Fig.3 Calculated calorific value of syngas from fluidized bed gasification of willow

Figure 3 shows the calculated lower heating value of syngas for the different feedstock. Gas calorific value changes very little as a result of the feedstock characteristics. Untreated willow appears to produce syngas with a slightly higher calorific value. The methane contribution is significant in the untreated feedstock and with an increase in hydrogen content resulting from the variations between feedstocks, the heating value is reduced as the feedstock is torrefied at higher temperatures.

Table 4

Syngas properties from fluidized bed gasification of torrefied and non-torrefied SV1 willow

\begin{tabular}{|c|c|c|c|c|c|c|c|c|c|c|c|c|}
\hline & \multicolumn{6}{|c|}{ Gas Composition (\% vol.) } & \multicolumn{6}{|c|}{ Gas Yield $\left(\mathrm{m}^{3} / \mathrm{kg}_{\text {daf }}\right)$} \\
\hline & $\mathrm{H}_{2}$ & $+/-$ & $\mathrm{CO}$ & $+/-$ & $\mathrm{H}_{2} / \mathrm{CO}$ & $+/-$ & $\mathrm{H}_{2}$ & $+/-$ & $\mathrm{CO}$ & $+/-$ & Total & $+/-$ \\
\hline Untreated & 16.59 & 0.58 & 22.63 & 0.57 & 0.73 & 0.03 & 0.34 & 0.02 & 0.46 & 0.03 & 2.02 & 0.08 \\
\hline @ $240{ }^{\circ} \mathrm{C}$ & 15.40 & 0.23 & 22.95 & 0.26 & 0.67 & $<0.01$ & 0.31 & $<0.01$ & 0.46 & 0.01 & 2.01 & 0.02 \\
\hline @ $260{ }^{\circ} \mathrm{C}$ & 19.02 & 0.54 & 21.65 & 0.43 & 0.88 & 0.01 & 0.54 & 0.02 & 0.47 & 0.02 & 2.24 & 0.04 \\
\hline @ $270{ }^{\circ} \mathrm{C}$ & 23.31 & 0.51 & 21.55 & 0.13 & 1.08 & 0.02 & 0.55 & 0.02 & 0.51 & 0.01 & 2.34 & 0.03 \\
\hline @ $280{ }^{\circ} \mathrm{C}$ & 22.82 & 0.24 & 19.99 & 0.41 & 1.14 & 0.02 & 0.58 & 0.02 & 0.50 & 0.02 & 2.47 & 0.08 \\
\hline
\end{tabular}

Table 4 shows gas yields and the Hydrogen and Carbon Monoxide concentrations in the syngas directly above the bed. The total gas yield increased from $2.02 \mathrm{~m}^{3} / \mathrm{kg}_{\text {daf }}$ to $2.47 \mathrm{~m}^{3} / \mathrm{kg}_{\text {daf }}$, an increase of $22(+/-4) \%$ over the untreated sample. The change in gas yield is most pronounced between the $240{ }^{\circ} \mathrm{C}$ and $260{ }^{\circ} \mathrm{C}$ conditions. Similarly, $\mathrm{H}_{2}$ yield increases by $70(+/-6) \%$ v/v and the $\mathrm{CO}$ yield increases by $9(+/-4) \% \mathrm{v} / \mathrm{v}$. The notable increases in $\mathrm{H}_{2}$ and $\mathrm{CO}$ yield were observed at torrefaction conditions greater than $240{ }^{\circ} \mathrm{C}$.

An increase in $\mathrm{H}_{2}$ concentration of approximately $38(+/-1) \% \mathrm{v} / \mathrm{v}$ above the data for the untreated condition was observed at steady state conditions. The $\mathrm{CO}$ concentration decreased by $12(+/-2)$ $\% \mathrm{v} / \mathrm{v}$. The resulting increase in the $\mathrm{H}_{2} / \mathrm{CO}$ ratio was $56(+/-4) \%$. The increase in $\mathrm{H}_{2}$ concentration between untreated and torrefied biomass is consistent with previous studies [13;14; 22]. However, Dudyński et al. reported a $3 \% \mathrm{v} / \mathrm{v}$ reduction in $\mathrm{CO}$ concentration between untreated and torrefied pellets while Couhert et al. reported a $20 \% \mathrm{~g} / \mathrm{g}_{\text {dry wood }}$ increase. Chen et al. observed a modest increase in $\mathrm{H}_{2}$ concentration at torrefaction temperatures of $270{ }^{\circ} \mathrm{C}$ and 290 
${ }^{\circ} \mathrm{C}$. These values were slightly lower than those observed for sawdust torrefied at $230{ }^{\circ} \mathrm{C}$ and 250

${ }^{\circ} \mathrm{C}$. In each case, the studies considered biomass types, torrefaction technologies, and gasifying reactors that were different than those used in this study.

The increase in syngas yield is likely attributable to the increased pore volume and surface area of the particles as reported by Chen et al. [14]. Chen and his colleagues found an increase in size and number of open pores for sawdust torrefied at $250{ }^{\circ} \mathrm{C}$ with more complicated pore structures occurring in samples torrefied between 270 and $290{ }^{\circ} \mathrm{C}$. The improvement in pore structure reduces the limitations on diffusion in the particles and increase the steam reforming and watergas shift reactions (WGS) during gasification. Furthermore, the relatively short residence time (or torrefaction time) used in the willow experiments may result in less plastic pore deformation and reduced clogging of the pores at higher temperatures when compared to Chen et al. The steam reforming and WGS effects would also be more pronounced in a BFB with good gasparticle mixing relative to the entrained flow reactors commonly used to investigate gasification of torrefied biomass. However, pore size and structure have not been measured and no conclusions can be made.

Finally, Figures 4 and 5 show the tar yield calculated according to equation 1 plotted against the mass fraction of polymers in the sample. Figure 4 shows tar concentration versus the lignin and cellulose composition. Clearly no correlation exists between these variables as treatment in the CTU had a small effect on the overall composition of cellulose and lignin. Figure 5 shows a correlation between the degradation of hemicelluloses and the concentration of tar in the syngas. Although the positive linear correlation is strong (Pearson's coefficient of 0.88), the direct proportionality between these two variables is unlikely. Others have reported significant decarbonisation reactions beginning to occur at $250^{\circ} \mathrm{C}$ [2]. Therefore, Figure 5 is better interpreted as showing a step or ramp change occurring around this point. The average tar concentration in willow torrefied at $240{ }^{\circ} \mathrm{C}$ and untreated willow is $17.26(+/-1.15) \mathrm{g} / \mathrm{m}^{3}$ compared to an average of $9.21(+/-1.13) \mathrm{g} / \mathrm{m}^{3}$ for willow torrefied at 260,270 and $280{ }^{\circ} \mathrm{C}$, a reduction of $47 \%$.

Both $\mathrm{H}_{2} / \mathrm{CO}$ and tar yield were affected by reducing the hemicelluloses fraction in the SRC willow by torrefaction. The main effect occurred when hemicelluloses were reduced to approximately $12 \% \mathrm{dw}$. No further significant changes were observed beyond this threshold. Furthermore, mildly torrefied SV1, defined by hemicelluloses fraction greater than $12 \%$ dw, was indistinguishable from untreated willow. The reduction in tar yield from torrefied willow, as it correlates to the fraction of hemicelluloses, could be ascribed to the improved pore structure and reduced oxygenation of the feedstock similar to the findings of Chen et al. [14]. Steam and oxygen are better able to access the deep surface of the torrefied particles and less likely to participate in the secondary and tertiary reactions that result in heavier hydrocarbons associated with tars. This type of key property data correlated to characterization is useful in design and optimization of process operations. 
Significant attempts have been made to report uncertainty in the relevant data. Gasification reactions are heavily dependent on reacting parameters. The experiments were designed to use fixed gasification reaction parameters and thereby observe the effects of torrefaction on syngas quality. The heterogeneous nature of the feedstock causes wide variations in the measured lignocelluloses composition. For example, the lignin fraction for the condition $240{ }^{\circ} \mathrm{C}$ varied from $26.4 \% \mathrm{dw}$ to $29.5 \% \mathrm{dw}$ resulting in the $3.8 \%$ uncertainty shown in Table 3 , where uncertainty is the standard error of the estimate multiplied by the t-value at the $95^{\text {th }}$ percentile. In this case, the uncertainty is likely the result of true variation in the feedstock rather than low measurement precision. To limit the uncertainty, careful adherence to standardized sampling and analysis techniques for biomass, such as NREL/TP-520-42620, is essential. Improved precision is possible by incorporating sieving into the process as described in section 10.5 of the NREL technical report. However, the process would no longer represent typical industrial operations due to the removal of components normally present in the biomass.

Gasification parameters also have a significant impact on syngas quality. The experimental design and actual parameters in Table 1 show several differences between the two values. Fluidization air during gasification of the untreated SV1 willow for example, is $12.7 \%$ below the design parameter of $0.071 \mathrm{~g} / \mathrm{s}$. Similarly, the fluidization air for the $270^{\circ} \mathrm{C}$ condition is $10.4 \%$ below the design parameter of $0.077 \mathrm{~g} / \mathrm{s}$. In both cases, the actual parameters reported in Table 1 fall within the bubbling regime for the reactor. Falling below the minimum fluidization velocity would significantly affect the syngas composition. Furthermore, variation in fluidization air would result in more or less oxidation of the fuel particles and change the syngas composition. A change in the extent of oxidation is reported as the equivalence ratio and is a critical factor in tar production. Milne et al. reported that many studies show tar reduction by increasing the equivalence ratio [17]. In this work, a high tar yield for the untreated and $270{ }^{\circ} \mathrm{C}$ conditions relative to the $240{ }^{\circ} \mathrm{C}, 260{ }^{\circ} \mathrm{C}$ and $280{ }^{\circ} \mathrm{C}$ conditions would have indicated an effect of the small reduction in ER shown in Table 1. High tar yield was not observed and the minor reduction in equivalence ratio for the untreated and $270{ }^{\circ} \mathrm{C}$ conditions, therefore do not affect the conclusions.

Fig.4 Tar yield in syngas for torrefied and non-torrefied SV1 willow versus lignin and cellulose composition in the biomass

Fig.5 Tar yield in syngas from torrefied and non-torrefied SV1 willow versus the hemicelluloses fraction. Error bars indicate random uncertainty at a $95 \%$ confidence level.

\section{Conclusions}

Short-rotation coppice willow was torrefied at four temperatures, characterized for lignocellulose composition and then gasified in a bubbling fluidized bed reactor with steam and air. The objective was to correlate syngas quality metrics with characteristics of the feedstock under fixed gasification conditions. The main conclusions from this work are; 
- The $\mathrm{H}_{2} / \mathrm{CO}$ ratio of syngas from BFB gasification was found to be greater for SV1 willow torrefied at temperatures greater than $240{ }^{\circ} \mathrm{C}$ when compared to untreated SV1 willow or lightly torrefied SV1 willow $\left(240^{\circ} \mathrm{C}\right)$.

- Under fixed temperature and equivalence ratio conditions, tar in the syngas changes measurably as the hemicelluloses begin to react (between 240 and $260{ }^{\circ} \mathrm{C}$ in this case). Syngas yield was found to increase from 2.02 to $2.47 \mathrm{~m}^{3} / \mathrm{kg}_{\text {dafSv1. }}$. A step change in tar concentration was observed from $17.26 \mathrm{~g} / \mathrm{m}^{3}$ to $9.21 \mathrm{~g} / \mathrm{m}^{3}$, a reduction of $47 \%$.

- There is a good positive linear correlation (Pearson's $r=0.88$ ) between the hemicelluloses in the feedstock and the concentration of tar in syngas from a fluidized bed gasifier. However, a linear correlation is unlikely to exist within a significant range of operation.

Ultimately, torrefaction of SRC willow to an extent that the treated biomass is composed of less than $12 \%$ dry weight hemicelluloses as measured by HR-TGA, will result in a more hydrogenrich, low-tar syngas from BFB, steam/air gasification.

\section{Acknowledgments}

The authors would like to thank Michelle Serapiglia from the USDA-ARS for her contribution to the characterization of willow samples.

This project is sponsored by SaskPower, the Prairie Agricultural Machinery Institute and the Applied Bioenergy Centre, the province of Saskatchewan Ministry of Agriculture - Agriculture Development Fund, the National Sciences and Engineering Research Council collaborative research and development grant, and Mitsubishi Hitachi Power Systems Canada. The authors greatly thank all of these sponsors for their valuable and continued support.

\section{References}

[1] Basu, P. (2010). Biomass gasification and pyrolysis (First edition.) Elsevier Inc.

[2] Medic, D., Darr, M., Shah, A., Potter, B., and Zimmerman, J. (2012). Effects of torrefaction process parameters on biomass feedstock upgrading. Fuel, 91(1), 147-154.

[3] Lipinsky, E. S., Arcate, J. R., and Reed, T. B. (2002). Enhanced wood fuels via torrefaction. American Chemical Society, Division of Fuel Chemistry, 47, 408-410.

[4] Van der Stelt, M., Gerhauser, H., Kiel, J., and Ptasinski, K. (2011). Biomass upgrading by torrefaction for the production of biofuels: A review. Biomass and Bioenergy, 35(9), 3748-3762. [5] Chew, J. J., and Doshi, V. (2011). Recent advances in biomass pretreatment-Torrefaction fundamentals and technology. Renewable and Sustainable Energy Reviews, 15(8), 4212-4222. [6] Chen, W., Peng, J., and Bi, X. T. (2015). A state-of-the-art review of biomass torrefaction, densification and applications. Renewable and Sustainable Energy Reviews, 44, 847-866. [7] Djomo, S. N., Kasmioui, O. E., and Ceulemans, R. (2010). Energy and greenhouse gas balance of bioenergy production from poplar and willow: A review. GCB Bioenergy, 3(3), 181. 
[8] Van Loo, S., and Koppejan, J. (2008). Biomass ash characteristics and behaviour in combustion systems. In S. Van Loo, and J. Koppejan (Eds.), The handbook of biomass combustion and co-firing (Second edition, pp. 249) Earthscan.

[9] Li, J., Brzdekiewicz, A., Yang, W., and Blasiak, W. (2012). Co-firing based on biomass torrefaction in a pulverized coal boiler with aim of 100\% fuel switching. Applied Energy, 99(0), 344-354.

[10] Eisentraut, A., Brown, A., and Fulton, L. (2011). Technology roadmap: Biofuels for transport.International Energy Agency.

[11] Bergman, P. C. A., and Kiel, J. H. A. (2005). Torrefaction for biomass upgrading. 14th European Biomass Conference and Exhibition, October 17-21, Paris, France.

[12] Prins, M. J., Ptasinski, K. J., and Janssen, F. J. J. G. (2006). More efficient biomass gasification via torrefaction. Energy, 31(15), 3458-3470.

[13] Couhert, C., Salvador, S., and Commandré, J. (2009). Impact of torrefaction on syngas production from wood. Fuel, 88(11), 2286-2290.

[14] Chen, Q., Zhou, J., Liu, B., Mei, Q., and Luo, Z. (2011). Influence of torrefaction pretreatment on biomass gasification technology. Chinese Science Bulletin, 56(14), 1449 - 1456.

[15] Steynberg, A., and Dry, M. (2004.). Fischer-tropsch technology. Amsterdam: Elsevier.

[16] McKendry, P. (2002). Energy production from biomass (part 1): Overview of biomass.

Bioresource Technology, 83(1), 37-46.

[17] Milne, T. A., Abatzoglou, N., and Evans, R. J. (1998). Biomass gasifier "tars": Their nature, formation and conversion.

[18] Hanaoka, T., Inoue, S., Uno, S., Ogi, T., and Minowa, T. (2005). Effect of woody biomass components on air-steam gasification. Biomass and Bioenergy, 28(1), 69-76.

[19] Yu, H., Zhang, Z., Li, Z., and Chen, D. (2014). Characteristics of tar formation during cellulose, hemicellulose and lignin gasification. Fuel, 118(0), 250-256.

[20] Sweeney, D. J. (2012). Performance of a pilot scale, steam blown, pressurized fluidized bed biomass gasifier. (PhD, University of Utah).

[21] Raut, M. K. (2014). Studies into the effect of torrefaction on gasification of biomass.

(MASc., Dalhousie University).

[22] Dudyński, M., van Dyk, J. C., Kwiatkowski, K., and Sosnowska, M. (2015). Biomass gasification: Influence of torrefaction on syngas production and tar formation. Fuel Processing Technology, 131, 203-212.

[23] Moersch, O., Spliethoff, H., and Hein, K. R. G. (2000). Tar quantification with a new online analyzing method. Biomass and Bioenergy, 18(1), 79-86.

[24] Cameron, K. D., Smart, L. B., Ballard, B., Abrahamson, L. P., and Volk, T. A. (2007). Salix dasyclados 'SV1'.http://www.esf.edu/: State University of New York College of Environmental Science and Forestry.

[25] Gerspacher, R., Campbell, W., Woytiuk, K., Evitts, R. W., and Phoenix, A. (2013).

Evaluation of a rotary-disc cutting machine for cutting long-stem biomass into uniform granules. (CANCAM 2013) 24th Canadian Congress of Applied Mechanics, Saskatoon, SK, Canada. [26] Campbell, W., Woytiuk, K., Evitts, R. W., Phoenix, A., and Gerspacher, R. (2012). Effect of temperature and time on torrefaction of Canadian prairie wheat straw. 4th International Symposium on Energy from Biomass and Waste, Venice, Italy.

[27] Serapiglia, M. J., Cameron, K. D., Stipanovic, A. J., and Smart, L. B. (2009). Analysis of biomass composition using high-resolution thermogravimetric analysis and percent bark content for the selection of shrub willow bioenergy crop varieties. BioEnergy Research, (1-2), 1-9. 
[28] Serapiglia, M., Gouker, F., Hart, J. F., Unda, F., Mansfield, S., Stipanovic, A., and Smart, L. (2015). Ploidy level affects important biomass traits of novel shrub willow (salix) hybrids.

BioEnergy Research, 8(1), 259-269.

[29] Parikh, J., Channiwala, S. A., and Ghosal, G. K. (2005). A correlation for calculating HHV from proximate analysis of solid fuels. Fuel, 84(5), 487-494.

[30] Barwick, V. (1999, April 13). Sources of uncertainty in gas chromatography and high performance liquid chromatography. Journal of Chromatography A, 849, 13-33.

[31] Serapiglia, M. J., Cameron, K. D., Stipanovic, A. J., Abrahamson, L. P., Volk, T. A., and Smart, L. B. (2013). Yield and woody biomass traits of novel shrub willow hybrids at two contrasting sites. BioEnergy Research, 6(2), 533-546.

[32] Fahmi, R., Bridgwater, A. V., Donnison, I., Yates, N., and Jones, J. M. (2008). The effect of lignin and inorganic species in biomass on pyrolysis oil yields, quality and stability. Fuel, 87(7), 1230-1240. 


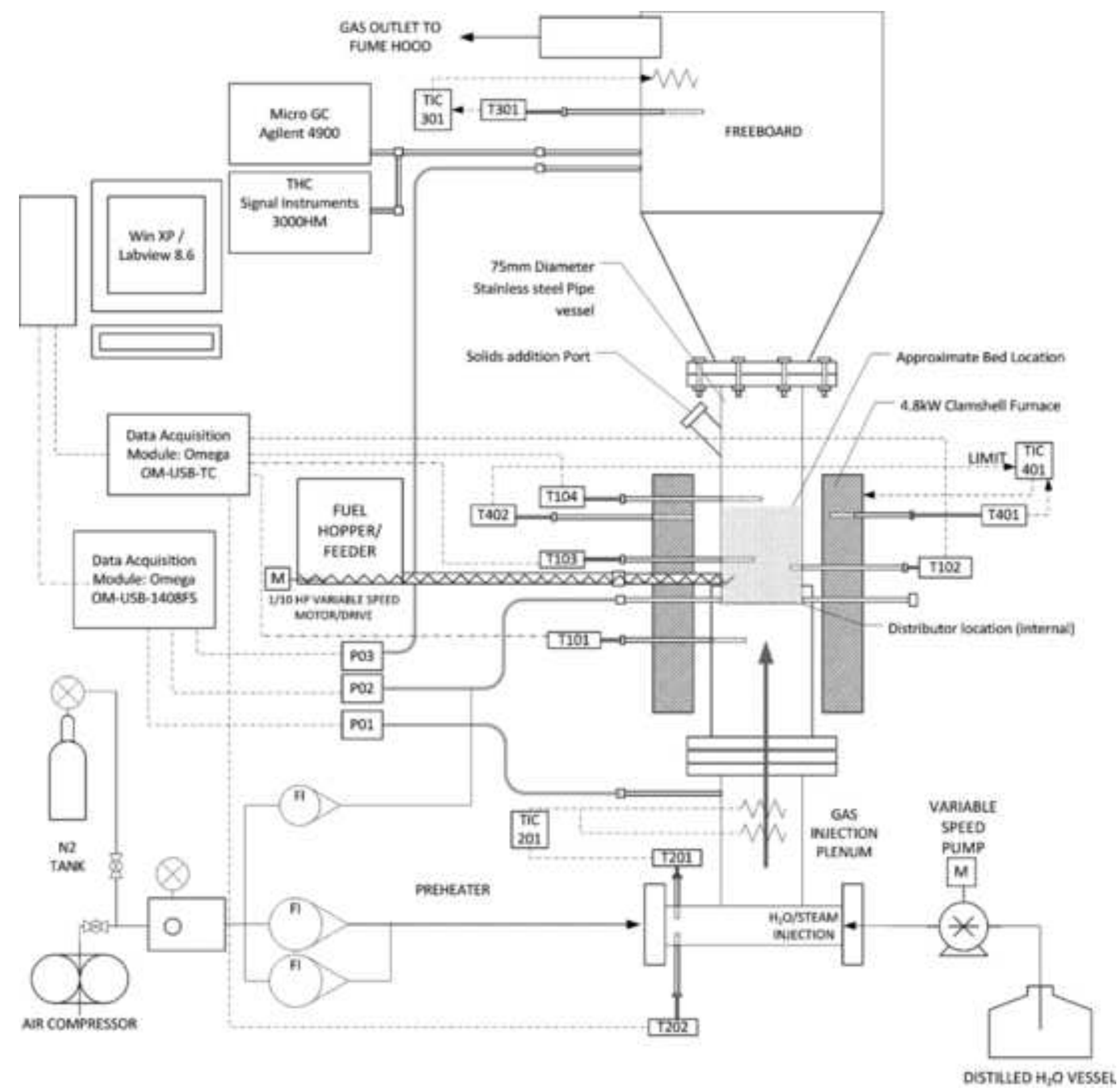




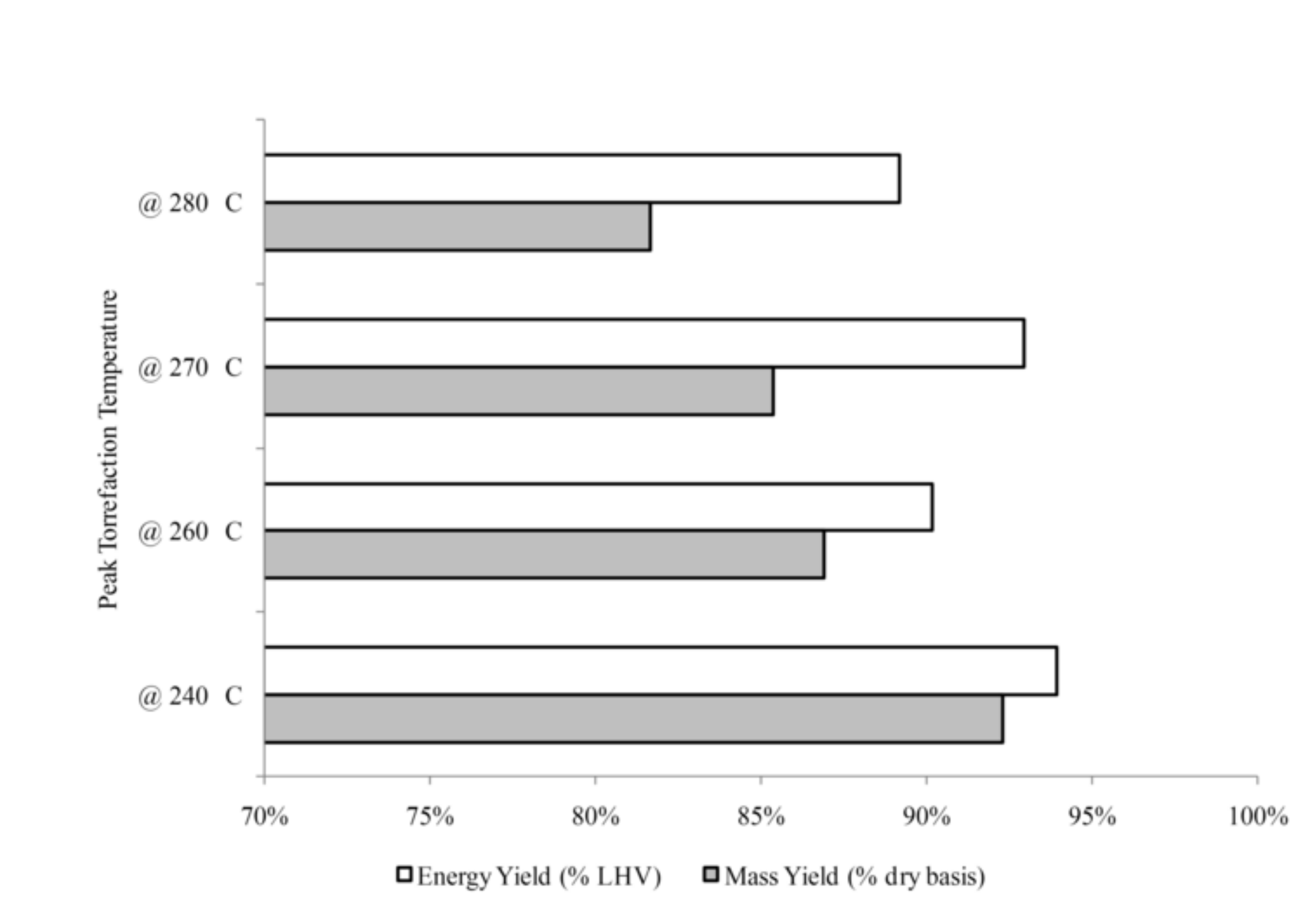

\section{Figure

.

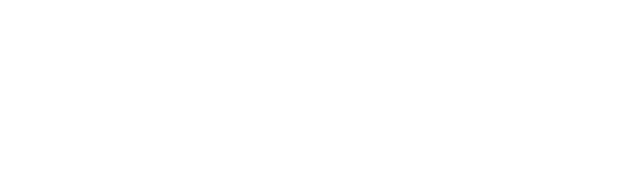

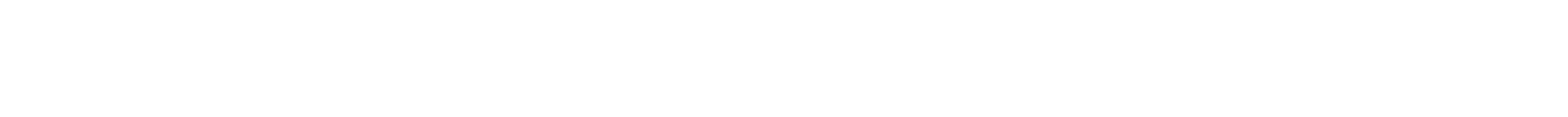
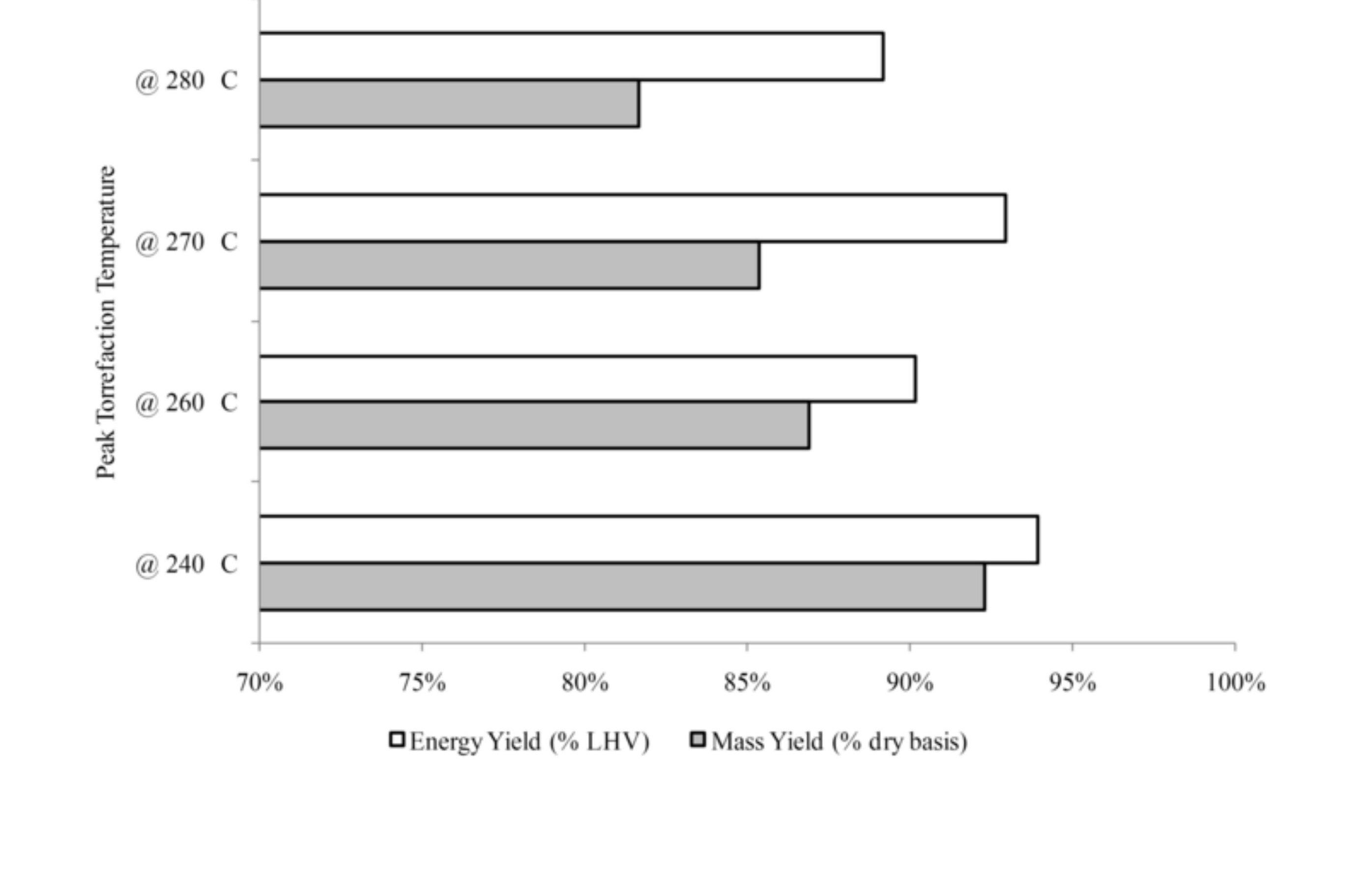

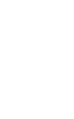

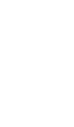




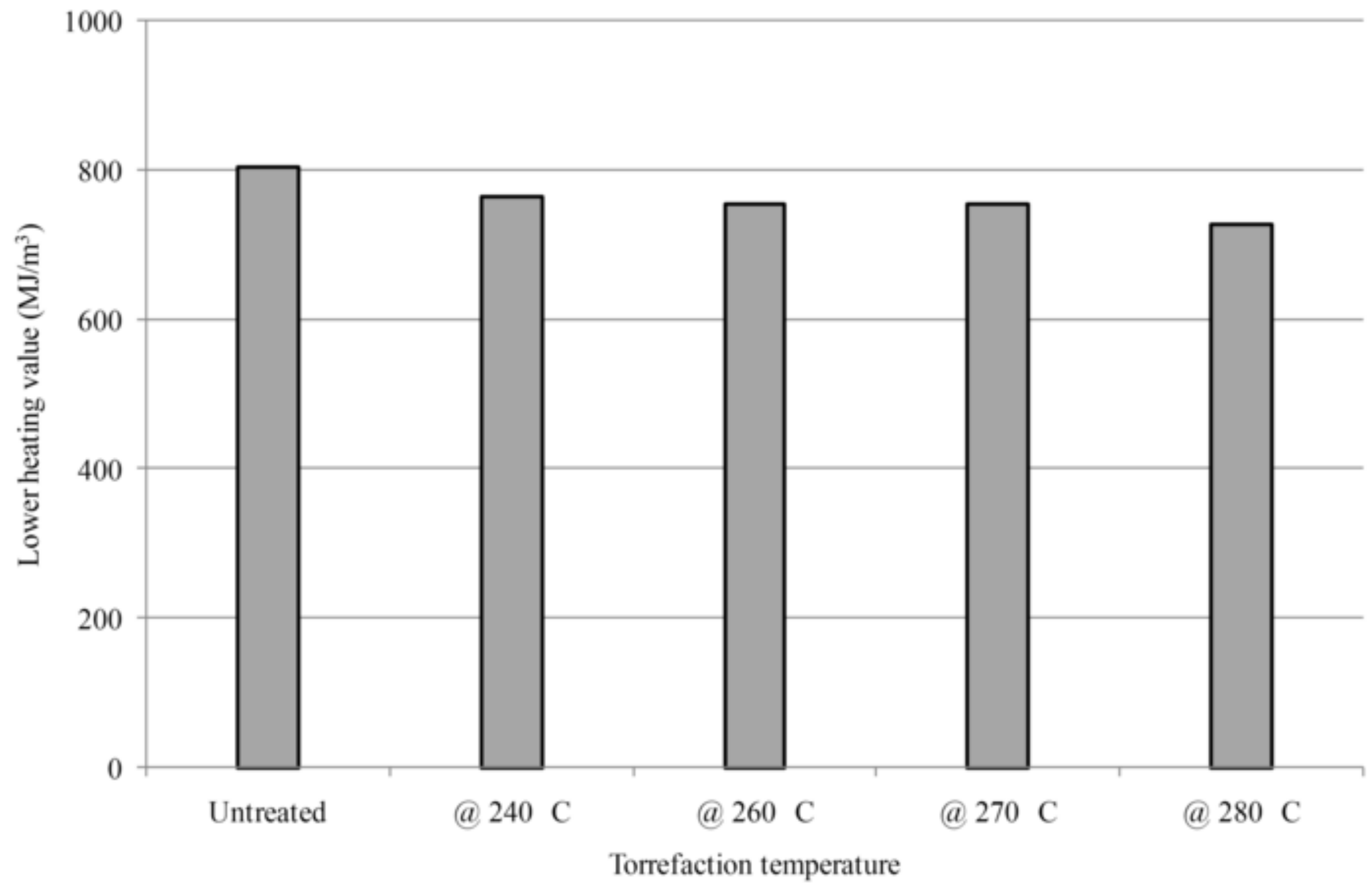




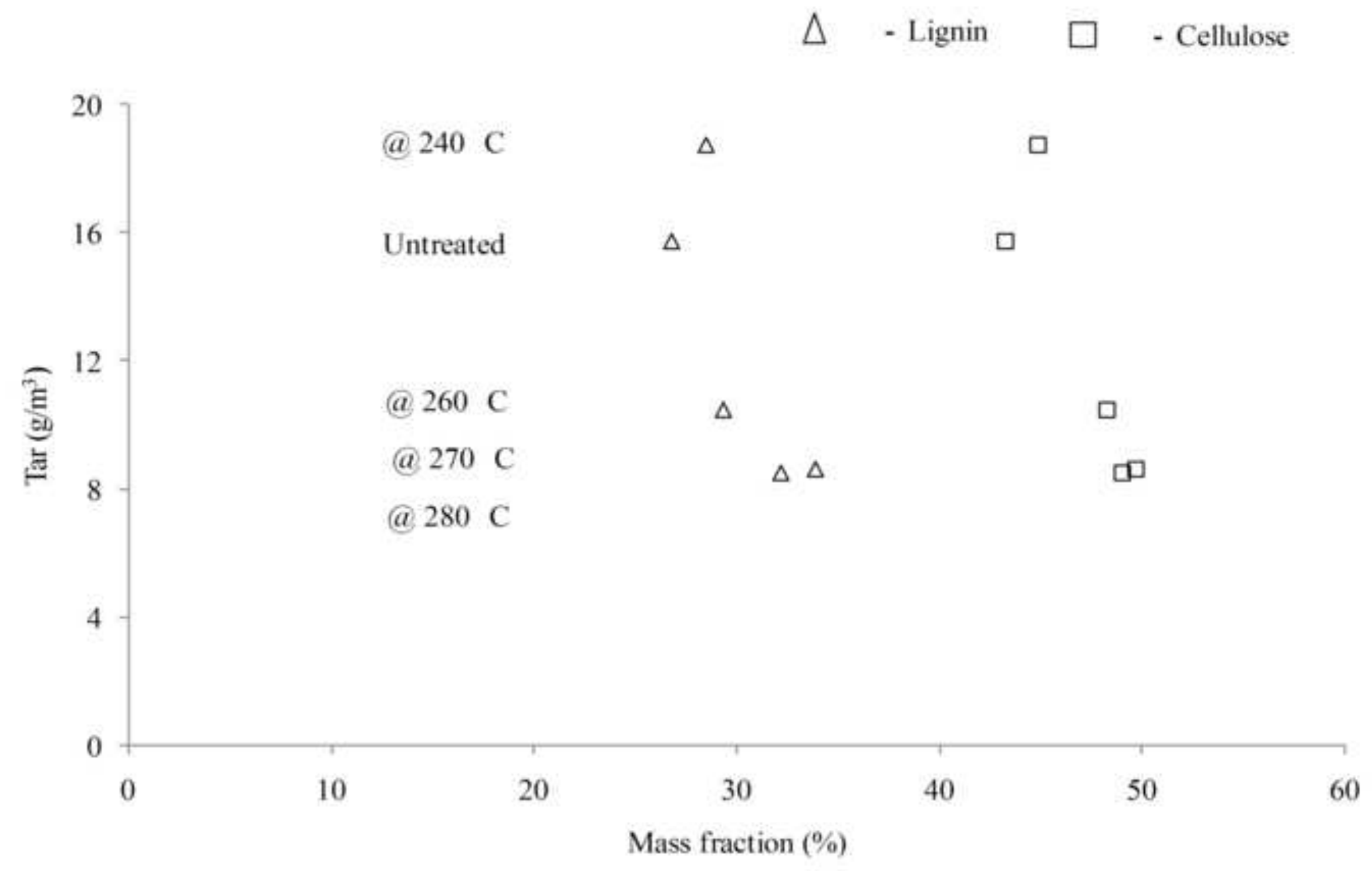




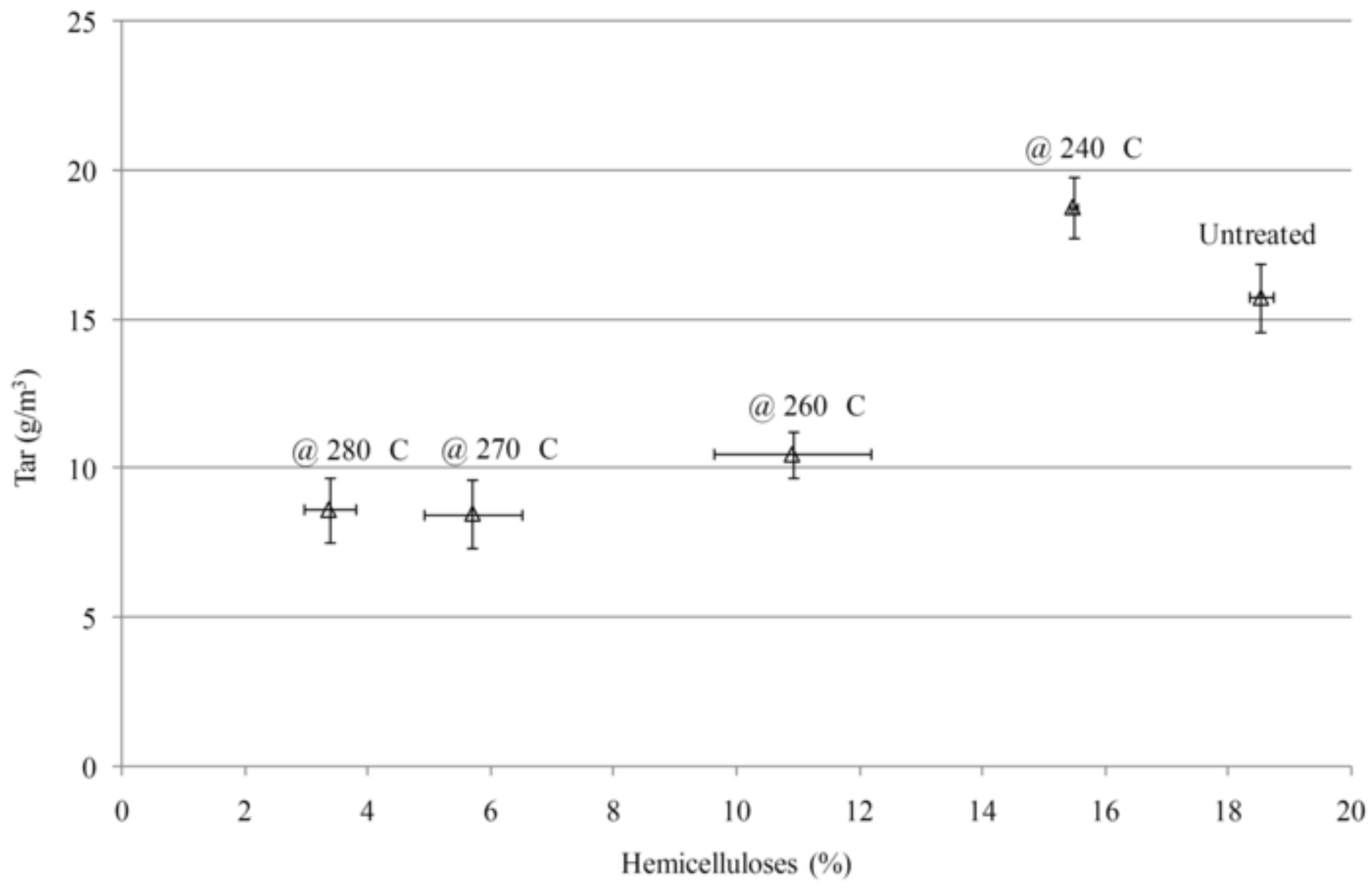

